\title{
Os "Últimos Refúgios" de Natureza Primitiva: As Reservas Biológicas e a Militância Ambiental de Augusto Ruschi (1940-1970)
}

\author{
The "Last Refuges" of Primitive Nature: The Biological Reserves and the \\ Environmental Militancy of Augusto Ruschi (1940-1970)
}

Alyne dos Santos Gonçalves *

[alyneazul79@gmail.com]

Recibido: 6 de diciembre de 2016

Aprobado: 12 de marzo de 2017

DOI:

Cita sujerida: Gonçalves, Alyne dos Santos. Os “últimos refúgios” de natureza primitiva: as reservas biológicas e a militânćia ambiental de Augusto Ruschi (1940-1970)." HALAC VII, no.1 (junio): 58-72.

\section{RESUMO}

Este artigo discute estratégias políticas de preservação do mundo natural, engendradas no interior de uma determinada relação homem/natureza, dada historicamente. Como estudo de caso, aborda aspectos da obra do naturalista capixaba Augusto Ruschi, no que tange ao processo de idealização e defesa de reservas florestais e biológicas no estado do Espírito Santo. A partir das redes científicas e políticas construídas desde os anos 19301940, Ruschi credenciou-se como protagonista do processo de determinação dos limites geográficos para a exploração socioeconômica dos recursos naturais capixabas. Por outro lado, sua influência não apresentou a mesma força nos anos 1960-1970, quando o modelo de desenvolvimento adotado naquele estado privilegiou a implantação de grandes projetos industriais. Em ambos os contextos, a proteção de fragmentos de "natureza primitiva" apresentou-se como um discurso estratégico diante de uma perspectiva utilitária de apropriação dos recursos naturais, sem, contudo, questionar a lógica do sistema capitalista.

\section{Palavras chave}

Reservas Biológicas, Redes Político-Científicas, Espírito Santo, Augusto Ruschi.

\section{ABSTRACT}

This article talks about policy strategies for preserving the natural world which were created inside a certain relationship man/nature, historically considered. As a case study, it approaches aspects of the work of the naturalist Augusto Ruschi, from Espírito Santo, regarding the process of idealization and defense of the Forest and biological resources in the State of Espírito Santo. From the scientific and political nets built since the years 1930-1940, Ruschi has become the protagonist of the process of determining the geographic limits for the social-economical exploitation of the natural resources from Espirito Santo. On the other hand, his influence was not so strong in the 1960-1970 when the developing model adopted in that State favored the implementation of great industrial projects. In both contexts, the protection of fragments of "primitive nature" was shown as strategic discourse before a useful perspective of natural resources appropriation without questioning the logic of the capitalist system.

\footnotetext{
* Mestrado em História pela Universidade Federal do Espírito Santo. Doutoranda em História pela UFES. Bolsista CAPES.
} 


\section{KEYWORDS}

Biological Resources, Political-Scientific Nets, Espírito Santo, Augusto Ruschi.

\section{INTRODUÇÃO:}

[...] as Reservas Florestais e Biológicas criadas em território espírito-santense [...] deverão permanecer intactas nos dias atuais, amanhã e sempre, para o eterno benefício dos filhos desse torrão. São elas os verdadeiros santuários que constituirão os últimos refúgios da fauna e flora silvestres que possuímos ${ }^{1}$.

As reflexões sobre a relação homem-natureza datam de muitos séculos. No mundo ocidental, 0 conceito de natureza é discutido ao menos desde a Antiguidade, com ênfase sobre os elementos que a definem em relação à cultura, bem como sobre sua influência na vida humana. Contudo, a noção de que a ação antrópica não apenas interfere no equilíbrio do mundo natural, mas é capaz de, no limite, levar à extinção da própria espécie humana e mesmo à destruição do planeta é essencialmente moderna. Segundo José Augusto Pádua, processos macro-históricos como a expansão colonial europeia, a institucionalização da ciência enquanto saber privilegiado acerca do mundo e a emergência de uma "sensibilidade ecológica", influenciada pelo trabalho de naturalistas e pela valorização romântica da natureza, motivaram reflexões filosóficas, científicas e políticas relativas aos impactos da ação humana sobre o mundo natural2.

As consequências socioambientais provocadas pela Revolução Industrial também contribuíram para a construção dessa nova sensibilidade, na medida em que a natureza passou a significar uma espécie de paraíso na terra, refúgio sagrado diante do ritmo frenético de funcionamento das sociedades urbano-industriais. Segundo Antonio Carlos Diegues, na segunda metade do século XIX a percepção romântica de reverência à natureza alimentou um movimento de base científica nos Estados Unidos chamado de preservacionismo, 0 qual defendia a criação de áreas naturais onde 0 homem seria apenas um visitante, jamais um morador. A ideia de proteger a natureza contra a ação destrutiva do homem influenciou, por sua vez, a criação de parques nacionais - 0 modelo norte-americano de salvaguarda de uma "natureza intocada" (wilderness), supostamente livre da intervenção humana ${ }^{3}$.

Em termos teóricos e políticos, esse movimento rivalizava com 0 conservacionismo, que, assumindo uma perspectiva instrumental ou pragmática em relação à natureza, defendia a possibilidade de exploração racional dos recursos naturais para o benefício da maioria, evitando o desperdício e melhorando sua qualidade para o gozo das gerações presentes e futuras, opondo-se, assim, ao que posteriormente foi chamado de "desenvolvimento a qualquer preço" 4 .

0 debate fomentado entre preservacionistas e conservacionistas nos Estados Unidos da América, no final do século XIX, repercutiu de maneira peculiar no Brasil, na medida em que foi apropriado por uma tradição - para usar o termo empregado por Pádua ${ }^{5}$ - de crítica político-ambiental desenvolvida por

\footnotetext{
${ }^{1}$ Ruschi, Augusto. 0 café e as florestas naturais do Estado do Espírito Santo. Boletim do Museu de Biologia Prof. Mello Leitão (BMBML), série Proteção à Natureza, nº 06, Santa Teresa, 28 de janeiro de 1951, p. 4.

2 Pádua, José Augusto. As bases teóricas da história ambiental. In: Franco, J. L. A.; Silva, S. D.; Drummond, J. A.; Tavares, G. G. (orgs.). História ambiental: fronteiras, recursos naturais e conservação da natureza. Rio de Janeiro: Garamond, 2012, pp. 17-37.

${ }^{3}$ Diegues, Antonio Carlos Sant'Ana. 0 mito moderno da natureza intocada. $6^{a}$ edição. São Paulo: Hucitec; Nupaub-USP/CEC, 2008, pp. 27-28. Segundo este autor, a ideia de wilderness ignorava ou omitia deliberadamente a histórica ocupação indígena de áreas consideradas "virgens", algo bastante conveniente no contexto oitocentista da Marcha para o Oeste norte-americana, de modo que os colonos brancos puderam gozar livremente do direito de ocupar o que acreditavam ser "terras vazias".

"4lbidem, p. 31. Sobre o preservacionismo e o conservacionismo, ver também Franco, José Luiz de Andrade; Drummond, José Augusto. Proteção à Natureza e Identidade Nacional no Brasil, anos 1920-1940. Rio de Janeiro: Editora Fiocruz, 2009 e Dean, Warren. A ferro e fogo: a história e a devastação da Mata Atlântica brasileira. São Paulo: Companhia das Letras, 1996.

${ }^{5}$ Em suas pesquisas sobre 0 lugar do Brasil na construção de uma consciência ecológica mundial, Pádua levantou cerca de 150 textos, produzidos por mais de 50 autores de diferentes regiões do país, em um período de pouco mais de um século (1786-1888), cujos trabalhos inauguraram uma "tradição" - no sentido da "existência de um conjunto de preocupações, temas e ideias que foram retomadas ao longo do tempo de forma recorrente e, em grande parte, acumulativa" - de crítica
} 
intelectuais luso-brasileiros desde 0 final do século XVIII, tradição esta que, senão amplamente disseminada na sociedade brasileira, ao menos bastante discutida e incorporada por cientistas da primeira metade do século XX.

0 amálgama entre 0 modelo estrangeiro de parque e a referida tradição expressou-se com clareza durante a Primeira Conferência Brasileira de Proteção à Natureza, realizada no Rio de Janeiro em 1934, com o patrocínio de Getúlio Vargas e a participação de diversas associações civis, cientistas e funcionários de governos estaduais, que, ali reunidos, defenderam a criação de parques e reservas naturais com base tanto em critérios estéticos e espirituais, como em argumentos utilitaristas de caráter econômico e científico. No Brasil das primeiras décadas do século $X X$, a adoção de elementos preservacionistas e conservacionistas encontrou coerência e organicidade em "um projeto maior que vinculava a natureza com a construção da nacionalidade"6.

0 naturalista capixaba Augusto Ruschi (1915-1986) foi um autêntico herdeiro dessa geração de conservacionistas, cujos nomes principais estavam ligados, de algum modo, ao Museu Nacional do Rio de Janeiro (MNRJ) ${ }^{7}$. Nascido em 12 de dezembro de 1915, na pequena cidade centro-serrana de Santa Teresa, interior do Espírito Santo - o oitavo dos doze filhos do engenheiro agrônomo Giuseppe Ruschi e da dona de casa Maria Roatti Ruschi, um casal de imigrantes italianos -, Augusto cresceu num ambiente de Mata Atlântica bastante preservada. Ainda muito jovem, despertou para o estudo dos beija-flores após descobrir, em 1934, que algumas espécies são responsáveis pela polinização de orquídeas ${ }^{8}$, tendo desenvolvido, anos mais tarde, técnicas para captura, transporte, criação e reprodução de beija-flores em cativeiro - nicho de pesquisa que o notabilizaria mundialmente.

Autodidata em taxonomia de animais e vegetais, sua primeira formação foi em Engenharia Agronômica (1934-1938), tendo começado o curso na Escola Superior de Agricultura e Veterinária de Viçosa/MG e colado grau na Escola Superior de Agricultura, Veterinária e Química Industrial de Campos/RJ. Mas logo o exímio coletor de espécies botânicas e zoológicas aproximou-se dos estudos biológicos, um campo do saber ainda em construção no Brasil, fruto de um processo de especialização da disciplina História Natural ${ }^{9}$.

Em 1939, ingressou no MNRJ como assistente voluntário da Seção de Botânica ${ }^{10}$, por indicação do renomado zoólogo Cândido Firmino de Mello Leitão. Dez anos mais tarde, em 26 de junho de 1949, fundou o Museu de Biologia Professor Mello Leitão - assim nomeado em homenagem ao mestre e amigo falecido em 1948 -, "com a finalidade de desenvolver pesquisas científico-biológicas, particularmente na região do Estado do Espírito Santo"11.

No mesmo movimento de inauguração do primeiro museu de história natural e instituto de pesquisas biológicas do Espírito Santo, Ruschi lançou o Boletim do Museu de Biologia Prof. Mello Leitão, que já nos primeiros fascículos da série "Proteção à Natureza", expressava sua filiação

ambiental, com base em uma visão política dos problemas nacionais, a saber: a crítica ao modelo de produção baseado no latifúndio, na monocultura e no trabalho escravo, com ampla destruição e desperdício dos recursos naturais. Cf. Pádua, J. A. Um Sopro de Destruição: Pensamento Político e Crítica Ambiental no Brasil Escravista (1786-1888). 2a Edição. Rio de Janeiro: Jorge Zahar, 2002, pp. 10-11.

${ }^{6}$ Franco \& Drummond. Proteção à Natureza..., p. 63.

${ }^{7}$ Refiro-me a Cândido Firmino de Mello Leitão (1886-1948), Alberto José de Sampaio (1881-1946), Frederico Carlos Hoehne (1882-1959), Edgard Roquette-Pinto (1884-1954), Heloísa Alberto Torres (1895-1946), entre outros.

${ }^{8}$ Ruschi, A coleção viva de Trochilidae do Museu de Biologia Prof. Mello Leitão, nos anos 1934 até 1961. BMBML, Série Biologia $n^{0} 30,26$ de Junho de 1961, p. 1.

${ }^{9}$ Sobre o processo de especialização e institucionalização da biologia no Brasil, ver Duarte, Regina Horta. A Biologia Militante: o Museu Nacional, especialização científica, divulgação do conhecimento e práticas políticas no Brasil - 1926-1945. Belo Horizonte: Editora UFMG, 2010.

${ }^{10}$ Em 06 de outubro de 1939, Ruschi obteve a inscrição de assistente voluntário da Seção de Botânica do Museu Nacional e, em 28 de maio de 1943, foi contratado para desempenhar a função de botânico. Sua efetivação no cargo veio apenas em 02 de dezembro de 1953, através da Portaria n 196, do Ministério da Educação e Cultura. Cf. Livro de admissões e contratos, depositado na Seção de Arquivo e Memória do MNRJ.

${ }^{11}$ Ruschi, Histórico e Fundação do Museu. Boletim Comemorativo do XXX Aniversário, Santa Teresa, 26 de junho de 1979 , p. 22. 
preservacionista-conservacionista ao defender as reservas de proteção integral da fauna e flora "primitivas" como santuários a serem preservados por seus benefícios estéticos e espirituais, mas também como laboratórios vivos a possibilitar o desenvolvimento das pesquisas biológicas:

A interligação existente entre essas finalidades, a de preservar e conservar perenemente 0 Patrimônio Natural dessas Reservas, e o desenvolvimento científico-cultural da sociedade, é tão real, como se aquela representasse o santuário e este os fiéis que o buscam. Não deixam de ser os laboratórios vivos, onde cientistas podem buscar uma infinidade de questões biológicas para estudá-las e os curiosos e amantes da natureza, que de certa forma, embora em menores proporções do que os Parques nacionais, servem de recreação ao espírito cansado das lutas do lufa-lufa quotidiano das cidades, uma vez que nelas pairam os rumores estranhos das máquinas em meio de atmosfera poluída pelos gases venenosos dos veículos ou das grandes fábricas industriais, para Ihe trazerem o silêncio de um mundo à parte, como se fora àquele do retorno do homem ao seu habitat primitivo, fazendo-o experimentar um passo longínquo da tranquilidade de espírito que tiveram seus antepassados, quando dos primórdios de seu aparecimento na face da Terra. $^{12}$

Embora o caráter sublime e espiritual da natureza fosse altamente relevante para a defesa que Ruschi fazia de sua proteção, tanto seus interesses científicos quanto o próprio contexto econômico e político em que viveu acentuaram em seu discurso a valorização utilitarista do mundo natural. Esta perspectiva, por sua vez, foi reforçada pelo juízo pessimista que fazia do "homem moderno", cuja ação "civilizadora" cobrava 0 alto preço da extinção de centenas de espécies da flora e fauna mundiais - não por necessidade, mas por simples "instinto de rapina, ódio, inveja". E, em razão desta postura beligerante frente à natureza - adquirida a cada comodidade material conquistada com 0 desenvolvimento tecnológico -, o homem moderno e civilizado deveria ser "excluído" dos locais destinados à manutenção do equilíbrio natural primitivo, a fim de que se salvasse o mínimo possível no inescapável devir civilizatório ${ }^{13}$.

Sua visão utilitária de conservação da natureza estava, pois, assentada em um sentido de urgência quanto à necessidade de proteger o maior número - ou, o mínimo possível - de áreas naturais primitivas. Diante de um modelo de desenvolvimento que já havia destruído parte monumental da Mata Atlântica, de um crescimento populacional que avançava em desproporção aos estoques naturais disponíveis, de um padrão de consumo absolutamente não condizente com 0 ritmo de regeneração da natureza, medidas estruturais, de longo prazo, que rompessem com o modelo de produção vigente e transformassem a mentalidade imediatista predominante, pareciam estar fora do campo de abordagem desse conservacionista, que, por isso, buscou avançar em seus propósitos utilizando as possibilidades disponíveis dentro da dinâmica socioeconômica posta.

A proposta deste artigo é apresentar uma breve análise das estratégias conservacionistas adotadas por Augusto Ruschi, considerando dois momentos históricos distintos: 0 final dos anos 1930 até início dos anos 1950, momento em que houve o processo de idealização, criação e demarcação de um conjunto importante de áreas naturais protegidas no Espírito Santo e os anos finais da década de 1960, estendendo-se pelos anos 1970, quando as condições econômicas e políticas locais motivaram uma intrincada mobilização pela transferência das reservas biológicas estaduais para a administração federal. Para tanto, é necessário ter em tela a concepção de proteção à natureza que orientou tais estratégias, bem como as redes políticas e científicas articuladas para tais fins e 0 contexto socioeconômico que engendrou aquelas intervenções. Meu principal objetivo é apresentar a um público mais amplo aspectos da obra desse naturalista capixaba, geralmente mais conhecido por suas pesquisas com beija-flores e orquídeas. Por outro lado, pretendo oferecer uma modesta contribuição para a história das áreas protegidas do Brasil, com a exposição dos desafios e conquistas obtidas nas lutas pelo seu estabelecimento.

\footnotetext{
${ }^{12}$ Ruschi, A. As Reservas Florestais e Biológicas do E. E. Santo. 0 critério adotado para a denominação dos córregos nelas existentes. 0 papel dessas Reservas Florestais de Proteção, no desenvolvimento Científico-Cultural da Sociedade. BMBML, Série Proteção à Natureza, $n^{\circ} 2,06$ de setembro de 1949, p. 9.

${ }^{13}$ Ruschi, Reflorestamento. BMBML, série Proteção à Natureza, n²1, 14 de novembro de 1954, p. 09.
} 


\title{
Redes político-científicas e estratégias de proteção à natureza: a criação de reservas biológicas no Espírito Santo (1940-1950)
}

\begin{abstract}
Salvar o mínimo indispensável do nosso patrimônio natural, é o que desejo para o bem de nossa Pátria e do nosso Estado, e por ele, envidarei todos os meus esforços, nada me fará recuar dessa decisão e dessa tarefa que assumi desde muito jovem ${ }^{14}$.
\end{abstract}

Para os conservacionistas brasileiros da primeira metade do século XX, "os termos proteção, conservação e preservação eram equivalentes e intercambiáveis" ${ }^{15}$, de modo que a proteção à natureza era justificada tanto por seu valor intrínseco, quanto por sua importância econômica, científica e política. Com efeito, a geração de cientistas ligados ideologicamente ao conservacionismo e institucionalmente ao MNRJ soube articular politicamente seu ideal de proteção à natureza ao projeto nacionalista que emergiu nos primeiros anos do Governo Vargas (1930-1934), envolvendo propostas pedagógicas de sensibilização popular para os cuidados com o mundo natural, vulgarização das pesquisas científicas, legislação ambientalmente responsável e justificação ideológica daquele projeto ${ }^{16}$.

Os instrumentos legais de proteção à natureza surgidos em 1934 - a exemplo do Código Florestal e do Código de Caça e Pesca -, bem como a criação dos primeiros parques nacionais em 1937 (Itatiaia) e 1939 (Serra dos Órgãos e Iguaçu), representaram uma primeira tentativa consistente e sistemática por parte do Governo federal no sentido de arbitrar sobre as formas de apropriação social dos recursos naturais - assim transformados em patrimônio naciona ${ }^{17}{ }^{17}$, tanto quanto a expressão institucional do relativo êxito obtido por aqueles cientistas, envolvidos nesses processos.

A demanda pela criação de parques, reservas biológicas e outros refúgios da vida selvagem ecoou pelas décadas seguintes e converteu-se no principal instrumento público de cuidados com o meio ambiente. A partir dos anos 1980, os críticos dessa estratégia, chamados de socioambientalistas, argumentavam que os conservacionistas dos anos 1920 e seus herdeiros, ao defenderem a não presença de seres humanos naquelas áreas, estariam protegendo a diversidade biológica em detrimento da diversidade cultural. Ou, em outras palavras, ao elegerem o modelo norte-americano de parques não habitados por humanos como principal estratégia - muitas vezes, a única - de proteção à natureza, esqueciam-se - ou ignoravam deliberadamente - a existência de povos indígenas e de comunidades ditas "tradicionais", de modo a recriar a dicotomia "povos" versus "parques" 18.

Os novos paradigmas da questão ambiental surgidos nos anos 1970-1980 tiveram como pano de fundo uma crítica sistêmica ao modelo capitalista de desenvolvimento e mesmo aos rumos tomados pelas sociedades sob o socialismo real, os quais não teriam viabilizado formas sustentáveis de relação homem-natureza. Segundo essa perspectiva, os cuidados com a natureza deveriam, necessariamente, incluir o tema da justiça social e da inclusão dos grupos marginalizados no debate público sobre os recursos naturais. Essa proposição convergia, no Brasil dos anos 1980, com demandas sociais que começavam a se manifestar no processo de redemocratização do país, a exemplo das lutas de

\footnotetext{
${ }^{14}$ Ruschi, A. Algumas observações sobre: Pipra rubrocapilla e Manacus manacus gutturosus e sua presença nas florestas de Santa Cruz no E. Santo. BMBML, série Biologia, n 52, 23 de maio de 1971, p. 9.

${ }^{15} \mathrm{~A}$ expressão é de Neide Esterci e Annelise Fernandez. 0 legado conservacionista em questão. Revista Pós Ciências Sociais, v. $6, \quad$ n. 12, São Luís-MA, 2009, pp. 15-40. Disponível em: <http://www.periodicoseletronicos.ufma.br/index.php/rpcsoc/article/view/50/37>. Acesso em 13 de julho de 2016 , p. 21.

${ }^{16}$ Cf. Franco \& Drummond, Proteção à Natureza...; Duarte, A Biologia Militante...

${ }^{17}$ Sobre o processo de patrimonialização da natureza no Brasil, ver Roncaglio, Cynthia. 0 emblema do patrimônio natural no Brasil: a natureza como artefato cultural. Curitiba, UFPR, 2007. 209 f. Tese (Doutorado em Meio Ambiente e Desenvolvimento). Programa de Pós-Graduação em Meio Ambiente - Universidade Federal do Paraná, 2007.

${ }^{18} \mathrm{Cf}$. Diegues, 0 mito moderno da natureza intocada... p. 39. Ver também Barreto Filho, Henyo. Notas para uma história social das áreas de proteção integral no Brasil. In: Terras Indígenas \& Unidades de Conservação da Natureza: 0 desafio das sobreposições. São Paulo: Instituto Socioambiental, 2004, p. 53-63. Disponível em <http://www.iieb.org.br/index.php/publicacoes/publicacoes-21/notas-para-uma-historia-social-das-areas-de-protecaointegra/> . Acessado em 20/07/2016.
} 
comunidades extrativistas do Acre, dos povos indígenas e comunidades tradicionais da Amazônia, entre outras $^{19}$.

Com efeito, nos escritos de Augusto Ruschi datados dos anos 1940-1950, pode-se notar uma forte crítica ao comportamento "irracional", "predatório" e "egoísta" do "homem moderno" em relação aos bens naturais, mas não a elaboração de uma crítica ao próprio modelo de desenvolvimento por ele adotado - embora demonstrasse a consciência de que a lógica da maximização de lucros e vantagens se dá em detrimento da natureza ${ }^{20}$. Antes, ele pretendia que se protegesse 0 mínimo de natureza primitiva, sem 0 prejuízo das atividades econômicas e científicas. É 0 que se pode ler no trecho que segue, de 1949, no qual recomendava, na qualidade de vice-presidente do Conselho Florestal do Estado do Espírito Santo, que todas as terras devolutas cobertas de floretas fossem consideradas "Reservas Florestais Estaduais", até que se fizesse um "levantamento fitofisionômico" das mesmas:

\begin{abstract}
Assim, vemos quão poucos anos nos restam, para verificarmos tal produto [madeiras de lei] na balança comercial do nosso Estado, e mesmo no perecimento da nossa Indústria madeireira. [...] Não terá solução 0 aspecto inicial do problema florestal, se tal medida não for tomada; pois, ainda impossível ser-nos-ia classificar as florestas protetoras, remanescentes, modelo e de rendimento. [...] E com isso, perde a ciência um dos grandes mananciais desconhecidos para 0 futuro de muitos ramos das ciências biológicas.

Não somos em absoluto daqueles que consideram crime irremediável para o erário público ou ainda para as ciências naturais, cortar uma árvore ou destruir um campo natural: Estas coisas tornam-se necessárias para a expansão da agricultura [...]. Somos daqueles que recomendam e pedem a conservação do essencial para a manutenção indefinida da biota e para isto não são necessárias muitas e nem grandes superfícies cobertas de florestas virgens. ${ }^{21}$
\end{abstract}

Desse modo, em um primeiro momento, os principais temas articulados por Ruschi à criação de reservas florestais foram a manutenção do estoque de madeiras para atendimento da demanda industrial e da balança comercial capixaba e, por outro lado, a preservação de fragmentos de natureza supostamente "virgens" para 0 desenvolvimento de pesquisas biológicas. Esta visão pragmática pode ser melhor compreendida no contexto histórico de sua articulação.

A partir da década de 1940, a exploração de madeiras no Espírito Santo - atividade exercida sistematicamente no estado pelo menos desde a virada para o século XIX - foi intensificada com a produção de dormentes para a construção de estradas de ferro, a construção civil, o consumo de lenha, a obtenção de carvão etc. Por sua vez, o aumento da demanda internacional por produtos derivados do ferro e do aço, devido especialmente às exigências armamentícias provocadas pela Segunda Guerra Mundial (1939-1945), ensejou a criação e instalação, em 1942, da Companhia Vale do Rio Doce (CVRD), aumentando consideravelmente as pressões sobre as florestas capixabas.

Consequentemente, observou-se um processo muito acelerado de destruição das florestas nativas - em especial, as do norte do estado, onde também se verificava a expansão das fronteiras para a lavoura de café: se entre os séculos XVI e XIX estima-se que o Espírito Santo tenha mantido entre 85\% e $90 \%$ de sua cobertura vegetal original, na virada do XIX para o XX esse percentual havia caído para $65 \%$, enquanto que durante a primeira metade do século XX a Mata Atlântica capixaba já havia sido reduzida a cerca de $1 / 3$ de sua cobertura original ${ }^{22}$.

\footnotetext{
${ }^{19}$ Esterci \& Fernandez, 0 legado conservacionista em questão...

${ }^{20}$ Ver, entre outros, Ruschi, $1^{\mathrm{a}}$ aula sobre Proteção e Conservação da Natureza e dos seus Recursos. BMBML, série Proteção à Natureza, $n^{\circ}$ 8, 26 de setembro de 1951; e Ruschi, $2^{\mathrm{a}}$ aula sobre Proteção e Conservação da Natureza e dos seus Recursos. $B M B M L$, série Proteção à Natureza, n 9, 14 de janeiro de 1952.

${ }^{21}$ Ruschi, A. Orientação para Defesa e Desenvolvimento do Patrimônio Florestal do Estado do Espírito Santo. BMBML, série Proteção à Natureza nº 01, 26 de junho de 1949, p. 03.

${ }^{22}$ Cf. Santos, Leonardo Bis dos. A criação de unidades de conservação no Espirito Santo entre 1940 e 2000: contextualização, conflitos e redes de interesse na apropriação social do meio ambiente. Vitória, UFES, 2016. 347 f. Tese (Doutorado em História). Programa de Pós-Graduação em História Social das Relações Políticas - Universidade Federal do Espírito Santo, 2016, pp. 109-110.
} 
A advertência secular para 0 perigo de escassez dos estoques naturais ${ }^{23}$ começou a ser efetivamente observada no Espírito Santo a partir da segunda metade dos anos 1930 - como vimos, um momento histórico relativamente favorável, no plano federal, a políticas de conservação da natureza. Em 1935, o interventor federal no estado, João Punaro Bley, criou o Conselho Florestal do Espírito Santo; em 1936, proibiu o corte de madeiras nas matas capixabas; em 1941, baixou o Decreto-lei $n^{\circ} 12.958$, pelo qual criava duas reservas florestais com $100.000 .000 \mathrm{~m}^{2}$ cada - uma em Linhares (então, distrito de Colatina), outra em Conceição da Barra ${ }^{24}$.

Entre o final dos anos 1930 e início dos anos 1950, Ruschi protagonizou o processo de idealização, levantamento e demarcaçã̉o de um grupo de reservas de proteção integral da fauna e flora capixabas, período este que coincidiu com sua formação no MNRJ e, portanto, com o momento de sua inserção em determinadas redes científicas e políticas, as quais o credenciaram junto às autoridades locais para intervir no referido processo - um movimento fundamental dentro de um contexto histórico no qual a administração pública funcionava por meio de decretos e que, portanto, não havia uma arena pública consolidada, na qual as demandas sociais pudessem ser institucionalmente expressas e, assim, disputar 0 amparo legislativo.

A ida de Ruschi para o MNRJ, em 1939, costuma ser atribuída a seu encontro, em 1937, em Santa Teresa-ES, com 0 entomólogo italiano Filippo Silvestri e com o zoólogo brasileiro Cândido Firmino de Mello Leitão. A reunião teria sido mediada pelo então secretário da poderosa pasta da Agricultura, Terras e Obras do Espírito Santo e futuro Governador, Carlos Fernando Monteiro Lindenberg - amigo e compadre de Mello Leitão e parente de Maria Stella de Novaes, a professora de história natural de Ruschi no Ginásio Espírito-Santense, em Vitória, com quem construiu sólida amizade ${ }^{25}$.

Segundo Carlos Lindenberg, seu encontro com o jovem Ruschi teria ocorrido por acaso, durante uma visita que fez ao prefeito de Santa Teresa - e irmão mais velho de Ruschi -, Enrico Aurélio Ildebrando Ruschi, o qual, sabendo do gosto de Lindenberg por orquídeas, convidou o secretário para visitar o orquidário de seu pai, na Chácara Anita, que 0 irmão havia transformado em "laboratório" de pesquisas botânicas e entomológicas. 0 volumoso e quase instintivo trabalho de coleta, classificação e organização em "caixinhas" dos "bichinhos" das florestas adjacentes teria causado tamanha impressão em Lindenberg, que este resolvera sugerir ao compadre Mello Leitấo a indicação de Ruschi para a então diretora do MNRJ, Heloísa Alberto Torres ${ }^{26}$.

Em 1938, Ruschi foi contratado por Lindenberg, por meio da Portaria $n^{\circ} 38$, de 27 de abril, para "prestar serviços junto ao Departamento Geral de Agricultura" do estado ${ }^{27}$. No documento não está especificado que função Ruschi deveria exercer, mas em um boletim de 1979, o cientista deu a seguinte indicação de seu vínculo formal com o Governo:

\footnotetext{
${ }^{23}$ Sobre 0 alerta quanto ao perigo de escassez de madeiras no Espírito Santo, ver os diferentes relatórios técnicos e de governo produzidos desde a segunda metade do século XVIII, elencados por Borgo, Ivan; Rosa, Léa Brígida Rocha de Alvarenga; Pacheco, Renato José Costa. Norte do Espírito Santo: Ciclo Madeireiro e Povoamento (1810-1960). Vitória: Edufes, 1996, p. 37 e ss.

$24 \mathrm{lbid}$.

${ }^{25} \mathrm{Cf}$. Almeida, Amylton de. Carlos Lindenberg - um estadista e seu tempo. Vitória, ES: Arquivo Público do Estado do Espírito Santo, 2010; Daniel, Sandra. Augusto Ruschi. (Coord.: Antônio de Pádua Gurgel). Vitória: Contexto, 2005; Biasutti, Luiz Carlos. No coração capixaba - 120 anos da colônia italiana Santa Teresa-ES. Belo Horizonte: Barvalle, 1994.

${ }^{26} \mathrm{Cf}$. Lindenberg apud Almeida. Carlos Lindenberg..., pp. 179-180. Há pelo menos duas outras versões para a entrada de Ruschi no MNRJ: uma em que ele próprio atribui a ressponsabilidade pela indicação de seu nome à Filippo Silvestri (Ruschi, $A$. Pasquim informa. Entrevista com Augusto Ruschi [outubro de 1977]. Entrevista concedida a Marcelo Cruz, Luiz Antônio Mello e Rosental Calmon Alves. Disponível em <http://ronaldmansur.blogspot.com.br/search?q= Augusto+Ruschi > . Acesso em 14 de junho de 2015); e uma segunda, na qual a vinda de Mello Leitão e Silvestri à Santa Teresa teria o intuito deliberado de conhecer pessoalmente o trabalho de Ruschi, do qual já teriam tido pelo menos uma amostra em 1932. Esta versão sequer toca no nome de Lindenberg, conferindo, ao invés disso, importante destaque à Maria Stella de Novaes, prima de Lindenberg (Duarte. A Biologia Militante..., pp. 133-134).

${ }^{27}$ Cf. documento inventariado por Gonçalves, Alyne dos Santos; Furtado, Marcello França. Catálogo do acervo textual de Augusto Ruschi no Instituto Nacional da Mata Atlântica (Museu de Biologia Prof. Mello Leitão). Vila Velha: Above publicações, 2015, p. 352.
} 
Daí em diante 0 Governo do E. Santo passou a dar atenção ao meu trabalho e auxiliou-me profundamente em minhas excursões de levantamento, colecionamento de material botânico e zoológico, dando-me condução, chaufeur e auxiliares de campo. [...] Com esses trabalhos de levantamento e de prospecção, inclusive determinando através de dados estatísticos de populações, quer da flora como da fauna, limitando-me às florestas virgens, com as espécies arbóreas de maior porte e da fauna de mamíferos, aves, répteis e anfíbios [...] terminei sugerindo a criação das Reservas Florestais e Biológicas de: Itaúnas; Córrego do Veado; Nova Lombardia; Pico da Bandeira. ${ }^{28}$

Na verdade, ao final deste trabalho, em 1948, Ruschi sugeriu a criação de sete reservas biológicas, mas, como ele próprio explicou em outro boletim, havia uma "avalanche de requerimentos de terras em andamento nessas áreas", de modo que só lhe foi possível proceder à demarcação de quatro delas $^{29}$. 0 fato é que houve, segundo 0 trecho acima, uma espécie de "parceria" entre 0 naturalista e 0 Governo do Espírito Santo: ao mesmo tempo em que o primeiro recebia apoios públicos para realizar suas pesquisas de campo, os resultados dessas pesquisas se revertiam em dados e informações demandadas pelo Estado.

Dessas informações, resultou o Decreto-lei $n^{\circ}$ 55, assinado em 20 de setembro de 1948, pelo agora Governador Carlos Lindenberg, que assim determinou a criação de sete reservas florestais e biológicas, cujas características foram expressamente definidas no texto da lei - a saber: no município de Conceição da Barra, uma reserva de flora halófila e outra de flora sub-higrófila; no município de Barra de São Francisco, uma reserva de flora de encostas; em Santa Teresa, uma reserva de flora de contrafortes da Serra da Mantiqueira; em Castelo, uma de flora alpina; em Afonso Cláudio, outra reserva de contrafortes da Serra da Mantiqueira; e nos municípios de lúna e Alegre, uma segunda reserva de flora alpina ${ }^{30}$.

Entretanto, das sete reservas estaduais criadas legalmente em 1948, apenas quatro foram efetivamente demarcadas por Ruschi entre os anos de 1948 e 1952, devido aos conflitos de interesses existentes entre empresários dos setores madeireiro e siderúrgico, colonos em busca de ocupar terras devolutas com atividades agropastoris e a própria ação estatal pela criação de áreas protegidas. Na década de 1950, a Companhia Vale do Rio Doce (CVRD) acirrou o nível desses conflitos, pressionando 0 governo do estado pela aquisição de áreas protegidas localizadas ao norte do Espírito Santo, a fim de aumentar a produção de dormentes para atender à expansão de sua malha férrea em direção ao centronorte do país ${ }^{31}$.

Se as redes científicas e políticas das quais Ruschi participou nos anos 1930-1940 possibilitaram que ele influenciasse decisivamente no processo de criação e demarcação de áreas naturais, estas mesmas redes - e outras novas, construídas, como veremos, nas décadas seguintes não foram suficientes para conseguir a criação de novas áreas de proteção ambiental ${ }^{32}$, conforme desejava Ruschi. 0 estabelecimento dos chamados "Grandes Projetos Industriais", a partir do final da

\footnotetext{
${ }^{28}$ Ruschi, Objetivos e destinos das Reservas Biológicas do Brasil. Boletim Comemorativo do XXX Aniversário, 26 de junho de 1979, p. 158.

${ }^{29}$ Ruschi, As Reservas Florestais e Biológicas do E. E. Santo. 0 critério adotado..., p. 03.

${ }^{30}$ Decreto-Lei $n^{\circ}$ 55, de 20 de Setembro de 1948, presente no Fundo Augusto Ruschi do Instituto Nacional da Mata Atlântica (INMA), nova denominação do Museu de Biologia Mello Leitão, Santa Teresa-ES. Código: BR.ES.INMA.AR.SEV.SAG.02. Ver também Ruschi, As Reservas Florestais e Biológicas do Estado do Espírito Santo e a Proteção à Natureza. Atos oficiais de sua criação. BMBML, série Proteção à Natureza, n 1 A, 26 de junho de 1949.

${ }^{31}$ Cf. Santos, A criação de unidades de conservação no Espírito Santo..., p. 156 e Borgo, Rosa \& Pacheco, Norte do Espirito Santo...; Santos. A criação de unidades de conservação no Espírito Santo...

${ }^{32}$ Ruschi afirmava ter influenciado na criação de outras três reservas biológicas no Espírito Santo: Comboios (entre os municípios de Linhares e Aracruz), em 1952, e Forno Grande (em Castelo) e Pedra Azul (em Domingos Martins), em 1960. Entretanto, as duas últimas já haviam sido legalmente criadas pelo decreto de 1948 - embora não tenham saído do papel até 1952 -, enquanto que a primeira funcionou como uma espécie de compensação para a reserva de Itaúnas - criada formalmente em 1948, mas jamais instalada na prática. Ver Ruschi, Objetivos e destinos das Reservas Biológicas..., p. $158 \mathrm{e}$ Santos. A criação de unidades de conservação no Espirito Santo..., pp. 160-161.
} 
década de 1960, priorizou a radical transformação da base produtiva capixaba, antes dependente da monocultura do café, forçando, assim, o deslocamento do discurso em favor da criação de reservas biológicas estaduais para a luta por sua transferência para a administração federal, em descompasso com 0 que ocorria em âmbito nacional, conforme veremos a seguir.

\section{Redes político-científicas e estratégias de proteção à natureza: a transferência de reservas biológicas para o domínio federal (1950-1970)}

A perspectiva desenvolvimentista inaugurada no Brasil pelo Governo Vargas foi ampliada e acelerada no Governo Juscelino Kubitschek. Seu Plano de Metas previa pesados investimentos em transporte, energia elétrica, produção de alimentos e bens de consumo duráveis. Tudo isso a partir de uma redefinição na relação entre poder público e privado, na qual o Estado passou a ser 0 principal financiador dos investimentos privados ${ }^{33}$.

0 empenho da administração JK em imprimir um ritmo acelerado de desenvolvimento no país provocou grande angústia nos atores preocupados com a preservação do ambiente natural. Wanderbilt Duarte de Barros, importante figura do conservacionismo brasileiro, expressou 0 assombro diante desse projeto da seguinte maneira: "O Presidente anunciou que vai desenvolver o país 50 anos em 5. Vai acabar com tudo" 34 .

Paradoxalmente, porém, no final do Governo JK, entre 1959 e 1961, foram criados cinco parques nacionais, a maioria deles na região Centro-Oeste: Araguaia (TO), Emas (G0), Brasília (DF), Aparados da Serra (SC-RS) e Ubajara (CE), num total de 772.367,55 hectares de áreas protegidas. Essa política teve continuidade no governo de Jânio Quadros (1961), com a criação de outros seis parques nacionais entre eles 0 do Caparaó (MG/ES) - e seis reservas florestais ${ }^{35}$. Barreto Filho observa que 0 boom de criação de áreas protegidas ocorrido nesse período acompanhou a "Marcha para o Oeste" brasileiro, isto é, o deslocamento planejado e programado do "ecúmeno nacional" para o interior do país, como uma estratégia de apropriação política do território pelo governo central ${ }^{36}$.

Embora os ideais conservacionistas de uso criterioso dos recursos naturais se chocassem, no fundamento, com 0 projeto nacional-desenvolvimentista inaugurado por Kubitschek, 0 Governo federal apoiava o discurso científico que lhes dava sustentação e que possuía ampla legitimidade social. De tal maneira que os cientistas conservacionistas souberam "justificar suas iniciativas, fazendo-as coexistir com os interesses desenvolvimentistas do Estado brasileiro" ${ }^{37}$.

É nesse contexto de rápido avanço industrial que surge a Fundação Brasileira para a Conservação da Natureza (FBCN), organização não governamental criada em agosto de 1958, na cidade do Rio de Janeiro, por um grupo de técnicos e cientistas interessados em "promover uma ação nacional" em favor do uso racional dos recursos naturais e da criação de "áreas reservadas de proteção" da natureza. 0 objetivo geral era fazer frente, de maneira organizada, aos apelos desenvolvimentistas do Governo JK ${ }^{38}$.

A partir de 1966, quando José Cândido de Mello Carvalho assumiu a presidência da FBCN, a instituição começou a viver uma fase mais dinâmica, construindo parcerias consistentes e duradouras

\footnotetext{
${ }^{33} \mathrm{Cf}$. Ribeiro, Diones Augusto. O Elo Perdido: 0 Conselho de Desenvolvimento Econômico do Espírito Santo - CODEC (19501980). Tese (Doutorado em História) - Programa de Pós-Graduação em História Social das Relações Políticas, Universidade Federal do Espírito Santo, Vitória, 2016. Ver também Silva, Marta Zorzal e. A Vale do Rio Doce na estratégia do desenvolvimentismo brasileiro. Vitória: EDUFES, 2004.

${ }^{34}$ Wanderbilt Duarte de Barros em entrevista a Urban, Teresa. Saudade do matão: relembrando a história da conservação da natureza no Brasil. Curitiba: Editora da UFPR; Fundação 0 Boticário de Proteção à Natureza; Fundação MacArthur, 1998, pp. 174-175.

${ }^{35} \mathrm{Ibid}$. Ver também Esterci \& Fernandez, 0 legado conservacionista em questão...

${ }^{36}$ Barreto Filho, Notas para uma história social das áreas de proteção integral no Brasil..., p. 57.

${ }^{37}$ Esterci \& Fernandez. 0 legado conservacionista em questão..., p. 20.

${ }^{38}$ Franco, J. L.; Drummond, J. A. 0 cuidado da natureza: a Fundação Brasileira para a Conservação da Natureza e a experiência conservacionista no Brasil: 1958-1992. Textos de História, vol. 17, nº 1, 2009, p. 62.
} 
como, por exemplo, com o Instituto Brasileiro de Desenvolvimento Florestal (IBDF) ${ }^{39}$, o qual se converteu em importante fonte de financiamento para seus projetos de pesquisa e conservação; e com entidades internacionais da projeção da International Union for Conservation of Nature and Natural Resources (IUCN). Estas e outras redes de cooperação e financiamento credenciaram aquela ONG, científica e politicamente, a participar ativamente da formulação de políticas públicas relativas ao meio ambiente, sobretudo no que toca à criação parques nacionais e reservas florestais. Vemos, assim, que esta segunda geração de conservacionistas, tal como a primeira, também apostava na criação de parques e reservas como principal instrumento de reação ao processo de urbanização e desenvolvimento do capitalismo ${ }^{40}$.

Augusto Ruschi militou nos quadros da FBCN como associado e, a partir de 1966, como membro da Comissão de Parques Nacionais e Reservas Equivalentes ${ }^{41}$, de onde cuidou em mobilizar os companheiros de ONG, bem como algumas instituições parceiras da Fundação, como o Ministério da Agricultura e o IBDF, no apoio às causas que abraçava em âmbito local - entre elas, a questão da transferência das reservas florestais capixabas para a tutela federal e de sua defesa contra sistemáticas invasões.

Segundo o cientista capixaba, desde 1952 houve um esforço para que as reservas estaduais fossem transferidas para a administração federal - "para evitar que os políticos viessem a presentear terras aos seus cabos eleitorais" 42 . De fato, devido a não destinação de recursos estaduais específicos para aquelas reservas, faltavam transportes, equipamentos, recursos humanos e outros elementos necessários à fiscalização e manutenção das mesmas, o que motivou o Governo do Espírito Santo a doálas para a União, mediante a Lei $n^{\circ} 976$, de $1955^{43}$.

Embora a recepção dessas reservas pela União tenha ocorrido apenas em 1963, por meio do Decreto federal $n^{\circ} 2.057$, houve muita pressão para que sua doação fosse sustada e, com isso, as áreas por elas ocupadas pudessem ser apropriadas para exploração de madeiras e outras atividades produtivas. A troca de correspondências entre Ruschi e diferentes personagens sobre esse tema revela, por um lado, as estratégias adotadas por empresas interessadas na permanência da tutela estadual sobre as reservas naturais e, por outro, um complexo jogo político de idas e vindas na delimitação de responsabilidades administrativas e de limites geográficos para a exploração socioeconômica dos recursos naturais capixabas. A análise dos movimentos desse jogo - ainda que panorâmica - indica 0 caráter precário de proteção daquelas áreas, cujos aspectos foram sendo construídos e consolidados mediante uma série de denúncias, pareceres e articulações que extrapolaram os marcos oficiais de sua recepção, uma vez que as investidas de Ruschi nesse sentido se estenderam até, pelo menos, 1977 -

\footnotetext{
${ }^{39} 0$ IBDF surgiu em 1967, no âmbito do Ministério da Agricultura, a partir da fusão entre órgãos governamentais responsáveis pelo fomento e regulamentação da explotação da madeira (Instituto Nacional do Pinho e Instituto Nacional do Mate) e órgãos de orientação conservacionista (Departamento de Recursos Naturais Renováveis e o Conselho Florestal Federal). Cf. Urban, Saudade do Matão...

${ }^{40} \mathrm{Cf}$. Esterci \& Fernandez, 0 legado conservacionista em questão...; Barreto Filho, Notas para uma história social das áreas de proteção integral no Brasil...

${ }^{41}$ Cf. FBCN. Boletim Informativo ${ }^{\circ}$ 2, Rio de Janeiro, Guanabara, 1967. Nos documentos da FBCN, Ruschi figurou como membro-associado; no entanto, ele reivindicou em mais de uma oportunidade o status de membro-fundador: "Embora tivesse participado da reunião preliminar para a criação da FBCN [...] não me foi possível [...] presenciar a reunião havida [...], na qual houve a criação dessa Instituição, com a formação da primeira diretoria, da qual constaram os nomes já referidos, [...] com exceção de Augusto Ruschi, o qual, entretanto, faz parte como um dos seus fundadores" (Ruschi. A Sociedade Brasileira de Proteção e Conservação da Natureza, e a Fundação Brasileira para a Conservação da Natureza. BMBML, série Proteção à Natureza $n^{\circ}$ 25, 21 de setembro de 1959, p. 04. Destaques meus). Ver também Ruschi. A Sociedade Brasileira de Proteção à Natureza. BMBML, série Proteção à Natureza n 14, 29 de novembro de 1953.

${ }^{42}$ Carta de Augusto Ruschi a Rubem Braga, datada de 20 de janeiro de 1966, presente no Fundo Augusto Ruschi... (sem codificação).

${ }^{43}$ A Lei n ${ }^{\circ}$ 976/1955 transferiu para a gestão da União as reservas florestais de Itaúnas (não demarcada), Córrego do Veado, Nova Lombardia e Pico da Bandeira, além de prever a transferência da Reserva de Comboios - depois que governo estadual tivesse meios de demarcá-la e indenizar proprietários e posseiros - e de fundir a Reserva de Barra Seca à de Sooretama (federal), legalmente criadas em 1941. Santos, A criação de unidades de conservação no Espírito Santo... pp. 162-163.
} 
portanto, 14 anos dèpois do decreto de 1963. Toda esta movimentação parece ter escapado do registro das fontes oficiais - inclusive o papel decisivo desempenhado por aquele cientista ${ }^{44}$.

Em um relato de 1967 ao jornalista e escritor Rubem Braga, Ruschi pediu ao conterrâneo e amigo que publicasse nos jornais artigos que 0 ajudassem a impedir que 0 Governo do estado cedesse à oferta da CVRD que, interessada na extração de madeiras para confecção de dormentes, teria proposto a doação do Edifício Cauê, em Vitória, para instalação da Assembleia Legislativa estadual em troca das áreas protegidas pelo IBDF: Sooretama, Nova Lombardia e Pinheiros ${ }^{45}$.

Poucos meses depois, um preocupado Ruschi escreveu mais uma vez ao amigo Rubem, a fim de relatar a visita surpresa que o Presidente da CVRD, Antonio Dias Leite, e o Prefeito de Santa Teresa, Waldyr Loureiro, Ihe fizeram no Museu. Segundo o naturalista, naquela ocasião Leite estava declaradamente vestindo "dois chapéus a um só tempo", isto é, representando, simultaneamente, os interesses da CVRD e da Aracruz Florestal. 0 objetivo era sondar-Ihe a opinião sobre as pretensões das duas empresas em utilizar áreas de reserva para reflorestamento com espécies exógenas (eucalipto e pinus) $)^{46}$.

As cartas escritas por Haroldo Edgard Strang e José Cândido de Mello Carvalho, datadas, respectivamente, de 22 e 24 de maio de 1967, demonstram que Ruschi mobilizou o prestígio e o canal institucional da FBCN para estabelecer diálogo com o IBDF, no sentido de pressioná-lo a se posicionar quanto às pretensões da CVRD e da Aracruz Florestal. 0 objetivo de ambas as missivas era tranquilizar Augusto com a informação de que o General Pinto da Luz, então presidente daquele Instituto, teria afirmado que não autorizaria a transação com a mineradora ${ }^{47}$.

As articulações de Ruschi junto à imprensa (por meio de Rubem Braga) e à administração federal (junto ao IBDF, através da FBCN) surtiram o efeito visado: as reservas federais no Espírito Santo não foram cedidas à exploração madeireira - para o que, segundo ele, também teria concorrido a influência presidencial: "Já há anos passados denunciei à Presidência da República a negociata de que se estavam beneficiando a Cia. Vale do Rio Doce trocando o Cauê Clube [...] por todas as áreas que constituíam as Reservas Biológicas do IBDF [...], mas, graças à compreensão e alto espírito do então Presidente da República, General Costa e Silva, essa pretensão foi afastada [...]". ${ }^{48}$

Entretanto, a ampla divulgação que 0 cientista conferiu ao tema parece ter motivado rusgas com autoridades locais, como indica a carta-resposta que escreveu em 09 de outubro de 1977 ao exGovernador Christiano Dias Lopes Filho, o qual teria se ressentido das entrevistas dadas pelo cientista, nas quais afirmava que "os três últimos Governos foram servis a grupos econômicos". Referindo-se, especificamente, à tentativa de permuta proposta pela CVRD durante a administração Dias Lopes (19671971), Ruschi assim justificou suas declarações públicas:

[...] o senhor sabe e o Brasil inteiro sabe [que a permuta] não se consumou, graças a minha interferência, que apelando para o Presidente Costa e Silva, enviando relatório de toda a ocorrência, ou negociata, solicitei-lhe fosse antes ouvido um técnico e com o resultado desse parecer, então se tomasse a medida cabível. [...] Ele ouviu o órgão competente e em absoluto 0 Presidente Costa e Silva não encomendou o parecer, como era de costume há anos, antes da Revolução. ${ }^{49}$

\footnotetext{
${ }^{44}$ De acordo com Leonardo Bis dos Santos, a memória bibliográfica das unidades de conservação localizadas no Espírito Santo - notadamente, Sooretama, Nova Lombardia, Córrego do Veado e Pico da Bandeira -, registrada em seus respectivos planos de manejo, omite os contratempos havidos no processo de sua recepção pelo Governo federal (ibid., p. 163). 0 papel desempenhado por Ruschi neste processo é uma dessas omissões.

${ }^{45}$ Carta de Augusto Ruschi a Rubem Braga, datada de 16 de maio de 1967. Poucos dias depois, em primeiro de junho, Ruschi volta a escrever ao amigo jornalista informando ter recebido seu primeiro artigo sobre 0 assunto (publicação não especificada). Ambas as cartas encontram-se no Fundo Augusto Ruschi... (sem codificação).

${ }^{46}$ Carta de Augusto Ruschi a Rubem Braga, datada de 07 de novembro de 1967, presente no Fundo Augusto Ruschi... (sem codificação).

${ }^{47}$ Ambas as cartas estão presentes no Fundo Augusto Ruschi... (sem codificação).

${ }^{48}$ Ruschi, Algumas observações sobre Pipra rubrocapilla..., p. 04.

${ }^{49}$ Carta de Augusto Ruschi ao ex-Governador Christiano Dias Lopes Filho, datada de 09 de outubro de 1977, presente no Fundo Augusto Ruschi... (sem codificação).
} 
Por outro lado, a mobilização construída pela manutenção e efetivação do domínio federal sobre as referidas reservas envolveu uma série de denúncias de Ruschi sobre as contínuas invasões perpetradas contra as mesmas, especialmente em relação à Reserva de Comboios ${ }^{50}$. De fato, entre 1971 e 1977, Ruschi produziu uma série de ofícios, cartas e relatórios sobre essas invasões, informando e pedindo providências às autoridades acionadas, ao mesmo tempo em que denunciava, entre outros agentes públicos, os governadores Dias Lopes Filho, Arhtur Carlos Gerhardt Santos (1971-1975) e Élcio Álvares (1975-1979) por conivência, grilagem de terras, extração irregular de areia etc. ${ }^{51}$

Temos assim um contexto histórico bastante diferente daquele vivenciado nos anos 1930-1940, quando a circunstância política de ter na chefia do governo do estado 0 amigo e apoiador Carlos Lindenberg pode ter contribuído para 0 acolhimento parcial das propostas conservacionistas de Ruschi. Diferentemente, nos anos 1960-1970, o cientista entrou em conflito com as principais lideranças políticas do Espírito Santo. Possivelmente, a falta de uma interlocução sensível às demandas conservacionistas dentro do governo capixaba, somada a um contexto econômico favorável à ampliação da indústria siderúrgica, ao estabelecimento de grandes eucaliptais e, consequentemente, ao crescimento urbano acelerado pela migração campo-cidade, provocou uma inflexão no discurso conservacionista de Ruschi, agregando a ele ingredientes sociais até então ausentes ou pouco acentuados.

\begin{abstract}
Lembro-me dos anos que os visitei [os índios remanescentes de tribos Tupiniquins] para estudos de ecologia, pois tinha 0 interesse de saber qual seria a área para cada índio viver em floresta virgem, sem que alterassem 0 ambiente, ou seja, que 0 ecossistema permanecesse inalterado [...]. Os Tupiniquins, com tais estudos, em Caieiras Velha, Potirí e outras pequenas áreas, necessitam em média de 300 a 350 hectares "per capita" de floresta, para sua sobrevivência nessa região estudada. Além dos Tupiniquins, muitos já alijados com a entrada do plantio de Eucalipto, mesmo em suas terras doadas pelo Império do Brasil, de cujas áreas a Aracruz se apossou e não possui o domínio, muitas outras áreas de pobres famílias ribeirinhas, também se apossou, banindo-as com ridículas indenizações, e às vezes com processos um tanto desumanos, [...] e ainda outras que foram mais cordatas, Ihe entregaram as terras por ninharias e foram para as favelas, em Vitória: único lugar para onde Ihes era permitido ir. [...] não é possível que na implantação de tal indústria florestal, em região de terrenos de topografia plana, de terras agricultáveis, onde a mecanização e a irrigação puderam ser introduzidas para 0 aproveitamento do plantio de cereais e gêneros de subsistência alimentar, quando 0 mundo reclama a falta de alimentos, no momento em que a OMS, Organização Mundial de Saúde, nos revela que mais de vinte milhões de seres humanos estão morrendo de inanição e mais de $2 / 3$ da população do mundo é carente de alimentos, vemos nessa área de um estado como $0 \mathrm{E}$. Santo, que só $30 \%$ são terrenos planos e suaves e os $70 \%$ restantes de terreno fortemente acidentados, e deixamos que tal venha a ocorrer, e, segundo é do meu conhecimento, o plano de expansão tanto da Aracruz Florestal, como da Docemade, pretendem plantar muitas centenas de milhões de árvores de eucaliptos nessas áreas planas, [...] as melhores terras agricultáveis [...] existentes no E. Santo ${ }^{52}$.
\end{abstract}

A longa citação justifica-se pela abundante presença de elementos daquilo que os socioambientalistas chamariam mais tarde de "justiça social", os quais começam a aparecer mais sistematicamente nos escritos de Ruschi a partir dos anos 1970. Neles, o naturalista articula pesquisa

\footnotetext{
${ }^{50}$ Criada pelo Decreto $n^{0} 1.376$, de 22 de junho de 1953, em substituição à Reserva Florestal de Itaúnas, a qual, embora criada em 1948, sequer havia sido demarcada cinco anos depois. Localizada entre os municípios de Aracruz e Linhares, Comboios apenas passaria à gestão da União em 1973 (cf. Santos, A criação de unidades de conservação no Espirito Santo...).

${ }^{51}$ Consultar a série: "Documentos Complementares" (subsérie: "Reserva Biológica de Comboios"), presente no Fundo Augusto Ruschi..., especialmente a carta endereçada ao Chefe do SNI, de 05 de maio de 1971 (código: BR.ES.INMA.AR.COM.RBC.01) e o ofício ao Presidente da Câmara Municipal de Aracruz-ES, de 06 de julho de 1977 (código: BR.ES.INMA.AR.COM.RBC.09).

${ }^{52}$ Ruschi, Algumas observações sobre: Pipra rubrocapilla..., p. 3. A mesma crítica aparece em outros boletins da década de 1970, a exemplo de Ruschi, 0 desaparecimento dos últimos remanescentes grupos indígenas do E. E. Santo. BMBML, série Proteção à Natureza, n 47, de 21 de abril de 1973.
} 
científica e proteção ambiental com os temas da expulsão de indígenas de suas legítimas terras; da migração forçada de pequenos posseiros e da consequente favelização das cidades; da importância de produzir alimentos, num quadro de fome mundial; enfim, da ilegalidade - e, de resto, da falta de bom senso - marcada no fato de a Aracruz ter se "apossado" das mais planas e agricultáveis terras capixabas.

Para além da dureza das palavras lançadas, em última instância, contra o modelo de crescimento econômico encampado pelo regime civil-militar, a particularidade das estratégias de proteção da natureza empregadas no Espírito Santo é ainda evidente quando comparada àquelas assumidas no âmbito nacional, especialmente por parte da FBCN, cujos membros articularam-se com os setores conservacionistas do IBDF e da Secretaria Especial de Meio Ambiente (SEMA) para criar novas áreas protegidas. De fato, entre 1979 e 1985 houve um segundo boom de criação de parques e reservas, quando foram estabelecidos dez parques nacionais, sendo quatro deles na região amazônica, e treze reservas biológicas, cinco delas nessa mesma região. Assim, esse novo ciclo de acolhimento federal das ideias e propostas conservacionistas coincidiu com 0 momento de expansão induzida das fronteiras agrícolas para o Centro-Oeste e Norte do país ${ }^{53}$.

Desse modo, houve uma "surpreendente convergência" entre os interesses territorialistas do nacional-desenvolvimentismo e as demandas conservacionistas de cientistas e técnicos lotados no IBDF, na SEMA e de militantes da FBCN, cuja "astúcia política" soube vincular a criação de novas áreas de preservação ao discurso nacionalista e de "segurança nacional" adotado pelo regime civil-militar pós1964, cuja escolha territorial para proteção - não por acaso - "recaiu justamente em zonas de interstícios dos pólos de desenvolvimento, funcionando como zonas de amortecimento destes e, ao mesmo tempo respondendo à pressão de organismos internacionais para a preservação de ecossistemas representativos da Amazônia"54.

Vale notar que uma parte dos generais de 64 se compreendia, ou ao menos se colocava publicamente como "uma espécie de reserva moral politicamente desinteressada e comprometida apenas com a Nação", estranha aos mesquinhos e contraditórios interesses particulares, os quais se constituiriam em "um entrave ao progresso e uma ameaça à segurança nacional". Daí seu apreço às medidas fundamentadas em critérios técnicos e científicos, capazes de thes franquear soluções "objetivas" para os problemas brasileiros ${ }^{55}$. Segundo Maria Tereza Jorge Pádua, "a própria disciplina militar contribuiu para que [os militares] respeitassem decisões de outros escalões. [...] defender uma área, cercar uma área contra os inimigos, é um raciocínio militar" ${ }^{56}$.

Ruschi não ficou alheio à estratégia de articular ciência, proteção à natureza e segurança nacional. Em carta de 15 de outubro de 1970 a Rubem Braga, criticou o "romantismo" ainda presente entre os . defensores da natureza e defendeu estratégias mais pragmáticas e articuladas com a política nacional:

Com todo o respeito e sinceros reconhecimentos que devemos aos pioneiros da proteção da natureza, nós devemos resolutamente confiar uma parte da direção entre as mãos de homens que vêm nela mais que uma borboleta a adejar asas ou um jacu-verde que esvoaça ou uma orquídea que esparge seu perfume atraente ao lado de sua beleza multicolor. Considerações objetivas e racionais devem determinar nossa atitude rumo à natureza [...]. Parece-me natural

\footnotetext{
${ }^{53}$ Esterci \& Fernandez, 0 legado conservacionista êm questão...; Barreto Filho, Notas para uma história social das áreas de proteção integral... Segundo estes autores (ibidem), a SEMA surgiu em 1973, no âmbito do Ministério do Interior, a partir de pressões internacionais pela proteção da natureza nos países em desenvolvimento, expressas tanto na Conferência de Estocolmo (1972), quanto nas condicionantes ambientais do BID e Banco Mundial para concessão de financiamento.

${ }^{54}$ Esterci \& Fernandez, 0 legado conservacionista em questão..., p. 20.

${ }^{55}$ Oliveira, Ueber José de. Configuração político-partidária do estado do Espírito Santo no contexto do regime militar: um estudo regional acerca das trajetórias de ARENA e MDB (1964-1982). Tese (Doutorado em Ciência Política) - Programa de Pós-Graduação da Universidade Federal de São Carlos, 2013, pp. 90-91.

${ }^{56}$ Maria T. J. Pádua, em entrevista a Urban, Saudade do matão..., p. 148, destaques meus. Observe a noção de oposição entre homem e natureza, presente na fala citada.
} 
pois que haja que assistir no presente uma notável mudança na parte ativa em que se equaciona 0 problema da natureza com a política de Segurança e Desenvolvimento Nacional ${ }^{57}$.

E foi justamente empregando essa gramática que Ruschi defendeu a transferência da Reserva de Comboios para o domínio federal, contra as invasões ali perpetradas: questão de Segurança Nacional, pela grandeza da Pátria e contra os interesses particulares de grandes indústrias e de membros "corruptos" do governo estadual. 0 fundamento técnico-científico também estava presente: tratar-se-ia de uma área sui generis no Brasil, formada de "restinga de clima tropical especial, em virtude de não haver no E. Santo e mesmo em outras restingas brasileiras, as características faunísticas e florísticas ali encontradas, sendo de importância principal o que ali ocorre com a desova da tartaruga de casco mole, ou tartaruga gigante: Dermochelís coriácea Linnaeus. É a única Reserva Biológica de Restinga em terras espiritosantenses" ${ }^{\prime 8}$.

Nesse sentido, a oposição de Ruschi a determinadas autoridades e opções econômicas identificadas com o regime civil-militar no Espírito Santo estava clara e incisivamente demarcada - muito embora isso não significasse para ele o prejuízo dos princípios morais e discursivos veiculados pela "Revolução"

\section{CONCLUSÃO}

A história da preservação de áreas naturais no Brasil costuma intrigar pessoas que se perguntam como é possível conciliar proteção ambiental e projetos desenvolvimentistas de grande impacto. 0 paradoxo surpreende ainda mais quando se sabe que muitas áreas transformadas em parques e reservas naturais eram - e ainda são - objeto de grande interesse de poderosas empresas ou indivíduos social e politicamente muito influentes. 0 breve exame de algumas das estratégias conservacionistas de Augusto Ruschi teve por objetivo acrescentar elementos para a compreensão dessa aparente contradição. Refirome, especialmente, à habilidade na construção e/ou mobilização de redes políticas e científicas, a fim de instrumentalizá-las para a intervenção nas políticas relativas aos recursos naturais, na ausência de uma esfera pública consolidada e de uma sociedade amplamente mobilizada sob bandeiras ambientais.

Desse modo, o pragmatismo predominante na visão de Ruschi sobre a natureza e sua proteção, aliado à projeção científica alcançada com suas pesquisas sobre beija-flores, orquídeas e reservas biológicas, ajudou a legitimar o discurso da urgente e necessária salvaguarda dos últimos fragmentos de natureza primitiva, sem que isso significasse, num primeiro momento, confronto direto com os poderosos interesses econômicos agro-exportadores que sustentavam 0 sistema produtivo vigente no Espírito Santo dos anos 1930-1940.

Por outro lado, mesmo reverberando as misérias de grupos sociais marginalizados e atacando publicamente importantes agentes políticos e empresariais das décadas de 1960-1970, a retaguarda conferida por aquelas articulações políticas e científicas, tanto quanto a gramática nacionalista vinculada

\footnotetext{
${ }^{57}$ Carta de Augusto Ruschi a Rubem Braga, datada de 15 de outubro de 1970. A mesma associação entre Proteção à Natureza e Segurança Nacional aparece em correspondência ao Pe. Raulino Reitz (Presidente do Congresso Nacional de Botânica), de 10 de janeiro de 1975, e ao jornalista Ronald Mansur, de 18 de fevereiro de 1975. As três correspondências estão presentes no Fundo Augusto Ruschi... (sem codificação).

${ }^{58}$ Ruschi, Objetivos e destinos das Reservas Biológicas do Brasil..., p. 158.

${ }^{59}$ Em diversas correspondências, Ruschi manifestou apoio e simpatia ao movimento de 1964, como neste trecho da carta enviada ao General Piculo Rodrigues Perlingero, datada de 11 de setembro de 1977: "E como sou revolucionário, que todas as $5^{\text {a }}$ Feiras, na Casa Amarela, em S. Paulo, com a presença de Assis Chateaubriand, José Maria Alkimim, Magalhães Pinto, Ademar de Barros, Carlos Lacerda, João Calmon, João Monteiro, Walter Moreira Sales e outros, fazia palestras sobre cousas do nosso patrimônio natural. Sou $0 n^{\circ} 1$ da Arena em meu Município. Espero que se moralize a nossa administração pública e se salve a natureza ameaçada, do Museu Nacional." Ou neste outro, escrito ao Almirante Blower, em 12 de setembro de 1977: "Imagine meu caro Almirante Blower, se a revolução entregar aos civis a Presidência, e muito mais se entregar a política nos Estados, antes de ouvir parte do público de bem. Pois os políticos são no meu Estado os maiores corruptos, naturalmente com raríssimas exceções". Ambas as missivas não codificadas, presentes no Fundo Augusto Ruschi... (sem codificação).
} 
a uma luta que, em ủltima instância, nada mais era que pedir para que a lei fosse cumprida (respeito aos limites legalmente estabelecidos para as reservas biológicas de proteção integral), teve 0 mérito de conferir alguma visibilidade e proteção às áreas finalmente assumidas pela administração federal.

Por fim, os meandros da história aqui narrados nos revelam, ainda, uma faceta pouco conhecida na biografia de Augusto Ruschi - qual seja: o protagonismo no processo de criação (legal) e de viabilização (demarcação e fiscalização) das primeiras áreas naturais do Brasil, provando, assim, ter sido mais que um especialista em beija-flores e orquídeas - algo que, por si só, não seria pouco. 